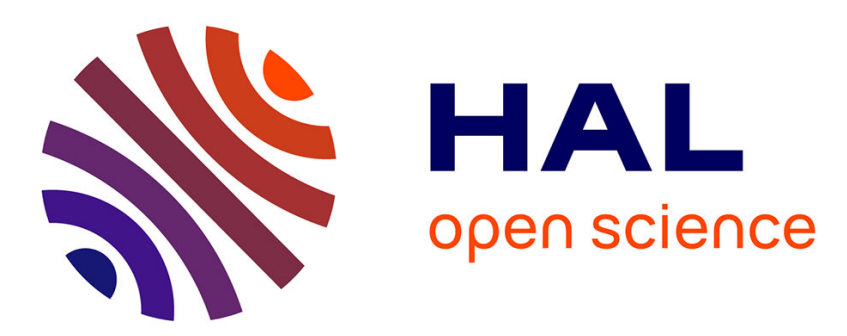

\title{
Electron transfer driven decomposition of adenine and selected analogs as probed by experimental and theoretical methods
}

\author{
T. Cunha, M. Mendes, F. Ferreira da Silva, S. Eden, G. Garcia, \\ Marie-Christine Bacchus-Montabonel, P. Limão-Vieira
}

\section{To cite this version:}

T. Cunha, M. Mendes, F. Ferreira da Silva, S. Eden, G. Garcia, et al.. Electron transfer driven decomposition of adenine and selected analogs as probed by experimental and theoretical methods. Journal of Chemical Physics, 2018, 148 (13), pp.134301. 10.1063/1.5021888 . hal-02108304

\section{HAL Id: hal-02108304 https://hal.science/hal-02108304}

Submitted on 3 Feb 2021

HAL is a multi-disciplinary open access archive for the deposit and dissemination of scientific research documents, whether they are published or not. The documents may come from teaching and research institutions in France or abroad, or from public or private research centers.
L'archive ouverte pluridisciplinaire HAL, est destinée au dépôt et à la diffusion de documents scientifiques de niveau recherche, publiés ou non, émanant des établissements d'enseignement et de recherche français ou étrangers, des laboratoires publics ou privés. 


\section{Electron transfer driven decomposition of adenine and selected analogs as probed by experimental and theoretical methods}

Cite as: J. Chem. Phys. 148, 134301 (2018); https://doi.org/10.1063/1.5021888

Submitted: 09 January 2018 . Accepted: 13 March 2018 . Published Online: 02 April 2018

T. Cunha, M. Mendes (D), F. Ferreira da Silva, S. Eden, G. García, M.-C. Bacchus-Montabonel (D), and P. Limão-Vieira (iD)

\section{ARTICLES YOU MAY BE INTERESTED IN}

Communication: Site-selective bond excision of adenine upon electron transfer

The Journal of Chemical Physics 148, 021101 (2018); https://doi.org/10.1063/1.5018401

Low-energy electron-induced dissociation in gas-phase nicotine, pyridine, and methylpyrrolidine

The Journal of Chemical Physics 147, 094303 (2017); https://doi.org/10.1063/1.4994679

An experimental and theoretical investigation into the electronically excited states of parabenzoquinone

The Journal of Chemical Physics 146, 184303 (2017); https://doi.org/10.1063/1.4982940
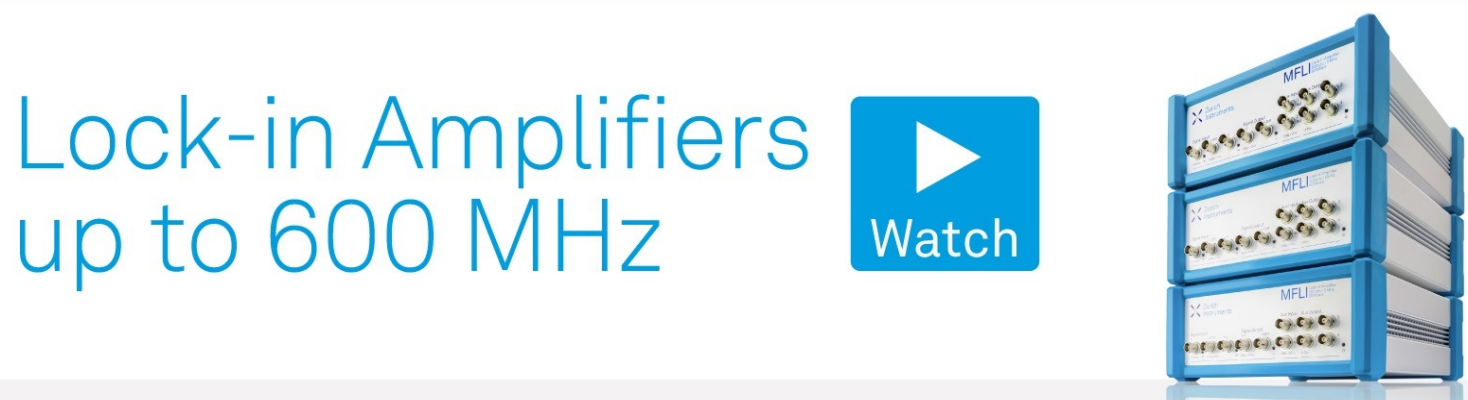


\title{
Electron transfer driven decomposition of adenine and selected analogs as probed by experimental and theoretical methods
}

\author{
T. Cunha, ${ }^{1}$ M. Mendes,${ }^{1}$ F. Ferreira da Silva,${ }^{1}$ S. Eden, ${ }^{2}$ G. García,${ }^{3}$ \\ M.-C. Bacchus-Montabonel, ${ }^{4, a)}$ and P. Limão-Vieira ${ }^{1, a)}$ \\ ${ }^{1}$ Atomic and Molecular Collisions Laboratory, CEFITEC, Department of Physics, Universidade NOVA \\ de Lisboa, 2829-516 Caparica, Portugal \\ ${ }^{2}$ School of Physical Sciences, The Open University, Walton Hall, MK7 6AA Milton Keynes, United Kingdom \\ ${ }^{3}$ Instituto de Física Fundamental, Consejo Superior de Investigaciones Científicas (CSIC), \\ Serrano 113-bis, 28006 Madrid, Spain \\ ${ }^{4}$ Institut Lumiére Matiére, Université Lyon, Université Claude Bernard Lyon 1, CNRS, \\ 69622 Villeurbanne, France
}

(Received 9 January 2018; accepted 13 March 2018; published online 2 April 2018)

\begin{abstract}
We report on a combined experimental and theoretical study of electron-transfer-induced decomposition of adenine (Ad) and a selection of analog molecules in collisions with potassium (K) atoms. Time-of-flight negative ion mass spectra have been obtained in a wide collision energy range (6$68 \mathrm{eV}$ in the centre-of-mass frame), providing a comprehensive investigation of the fragmentation patterns of purine $(\mathrm{Pu})$, adenine $(\mathrm{Ad})$, 9-methyl adenine (9-mAd), 6-dimethyl adenine (6-dimAd), and 2-D adenine (2-DAd). Following our recent communication about selective hydrogen loss from the transient negative ions (TNIs) produced in these collisions [T. Cunha et al., J. Chem. Phys. 148, 021101 (2018)], this work focuses on the production of smaller fragment anions. In the low-energy part of the present range, several dissociation channels that are accessible in free electron attachment experiments are absent from the present mass spectra, notably $\mathrm{NH}_{2}$ loss from adenine and 9-methyl adenine. This can be understood in terms of a relatively long transit time of the $\mathrm{K}^{+}$cation in the vicinity of the TNI tending to enhance the likelihood of intramolecular electron transfer. In this case, the excess energy can be redistributed through the available degrees of freedom inhibiting fragmentation pathways. Ab initio theoretical calculations were performed for 9-methyl adenine (9-mAd) and adenine (Ad) in the presence of a potassium atom and provided a strong basis for the assignment of the lowest unoccupied molecular orbitals accessed in the collision process. Published by AIP Publishing. https://doi.org/10.1063/1.5021888
\end{abstract}

\section{INTRODUCTION}

It is now well-established within the international scientific community that low-energy electrons (e.g., $<15 \mathrm{eV}$ ), as the most abundant secondary species produced by ionising radiation, play an important role in the modification of critical molecular structures in biological material. Such electron induced molecular decomposition processes have been demonstrated to yield substantial damage in plasmid DNA through single- and double-strand breaks. ${ }^{1}$ Low-energy electrons can efficiently attach to DNA molecular constituents and derivatives to form transient negative ions (TNIs), which can subsequently dissociate and have been probed extensively in recent years using both experimental and theoretical methods. ${ }^{2}$ Under aqueous conditions that approximate biological environments, TNI resonances can be shifted to lower energies. ${ }^{3}$ Furthermore Wang and co-workers ${ }^{4}$ found that significant quantities of single- and double-strand breaks of irradiated aqueous DNA are induced by pre-hydrated electrons. Wang

\footnotetext{
a)Authors to whom correspondence should be addressed: plimaovieira@ fct.unl.pt, Tel.: (+351) 212947859 and bacchus@univ-lyon1.fr, Tel.: (+33) 472431083 .
}

et al.'s experiments on each deoxyribonucleotide [dXMP, where $\mathrm{X}$ represents thymine, cytosine, guanine, or adenine] have also shown that dGMP and dAdMP are more efficient at capturing pre-hydrated electrons than dTMP and dCMP. Since most of the radiation damage in cellular DNA occurs through the generation of reactive species within the surrounding water, Wang et al.'s proposed mechanism of dissociative electron transfer may be responsible for a large portion of such damage. Given this rationale, electron transfer seems to be more prevalent under physiological conditions rather than free electron attachment processes. Therefore we consider that the present data on collisional electron-transfer-induced dissociation of selected purine targets may have future applications in nanoscale models of radiation damage in DNA. By carrying out potassium-impact mass spectrometry experiments on partially labeled derivatives of adenine (Ad) and by means of quantum chemical calculations, we have explored the fragmentation patterns of negative ions formed in charge-transfer collisions.

Electron interactions with adenine $\left(\mathrm{C}_{5} \mathrm{H}_{5} \mathrm{~N}_{5}\right)$ are well represented in the literature, including dissociative electron attachment (DEA) experiments, ${ }^{5,6}$ electron impact ionisation studies, ${ }^{7}$ and charge-exchange collisions with laser-excited 
Rydberg atoms to probe dipole-bound anions. ${ }^{8}$ Aflatooni et al.' $\mathrm{s}^{9,10}$ electron transmission data placed the three lowest electron affinities of $\pi^{*}$ character at $0.54,1.36$, and $2.17 \mathrm{eV}$. More recently, site-selective bond excision of adenine yielding the dehydrogenated parent anion upon electron transfer in collision with neutral potassium atoms has been reported. ${ }^{11}$ The influence of functional groups on site-specific dissociation of DNA bases by low-energy electron impact has been demonstrated via an effective loss of hydrogen located at the specific nitrogen positions. ${ }^{12-14}$ As far as theoretical investigations are concerned, we note elastic-scattering cross sections and resonance energies for low-energy electron impact on DNA/RNA bases, ${ }^{15}$ bound anionic states of adenine tautomers explored at the B3LYP/6-31+G** level of theory, ${ }^{16}$ vertical and adiabatic ionisation energies of 12 adenine tautomers, ${ }^{17}$ geometrical structures and energetic properties for different tautomers of adenine using multi-configurational wave functions, ${ }^{18}$ and electronic spectra of purines ${ }^{19}$ and purine tautomers. ${ }^{20} \mathrm{Com}$ prehensive studies on dissociative photoionisation of adenine following valence excitation ${ }^{21}$ and reactivity in adenine-water clusters in multi-photon and electron impact ionisation studies $^{22}$ have been also reported. Finally, hydrodynamic simulations have indicated that sequential $\mathrm{HCN}$ addition can be responsible for adenine formation during molecular cloud collapse. ${ }^{23}$ Quantum chemical studies have recently shed light on the role of $\mathrm{HCN}$ and other prebiotic oligomers (e.g., $\mathrm{HCCN}$, $\mathrm{NH}_{2} \mathrm{CN}$, and $\mathrm{CN}$ ) to participate in the gas-phase (and in the grain-phase) radical-radical and radical-molecule reactions on adenine formation within the interstellar medium. ${ }^{24,25}$

\section{EXPERIMENTAL METHOD}

The crossed molecular beam setup used to study collisions of neutral potassium $(\mathrm{K})$ atoms with neutral purines has been described in detail previously. ${ }^{26,27}$ Briefly, an effusive target molecular beam crosses a primary beam of fast neutral $\mathrm{K}$ atoms and the product anions are analysed using a homebuilt linear time-of-flight (TOF) mass spectrometer. The K beam is produced in a resonant charge exchange chamber from the interaction of $\mathrm{K}^{+}$ions from a potassium ion source (12$100 \mathrm{eV}$ in the lab frame) with gas-phase neutral potassium atoms from an oven source. Residual ions were removed from the primary beam by electrostatic deflecting plates outside the oven. The intensity of the neutral potassium beam was monitored using a Langmuir-Taylor ionisation detector before and after the collection of each TOF mass spectrum. The beam energy resolution in the present collision energy range was measured as $\sim 0.5 \mathrm{eV}$ (FWHM) using a hemispherical electrostatic energy loss analyser to characterise the $\mathrm{K}^{+}$ion signal at a fixed energy following $\mathrm{K}$ collisions with nitromethane. The effusive beam of purines from an oven source was admitted into vacuum through a $1 \mathrm{~mm}$ diameter capillary where it was crossed with the neutral fast potassium beam. Negative ions formed in the collision region were extracted by a $250 \mathrm{~V} \mathrm{~cm}^{-1}$ pulsed electrostatic field. The typical base pressure in the collision chamber was $6 \times 10^{-5} \mathrm{~Pa}$ and the working pressure was $4 \times 10^{-4} \mathrm{~Pa}$. Mass spectra (resolution $\mathrm{m} / \Delta \mathrm{m} \approx 125$ ) were obtained by subtracting background measurements (without the heated sample) from the sample measurements.
Mass calibration was carried out on the basis of the well-known anionic species formed after potassium collisions with nitromethane. ${ }^{28}$ Purine (Pu), adenine (Ad), 9-methyl adenine (9-mAd), and 6-dimethyl adenine (6-dimAd) were supplied by Sigma Aldrich with stated purities of $98 \%, \geq 99 \%$, $97 \%$, and $\geq 98 \%$, respectively. Adenine-2-d (2-DAd) was supplied by CDN Isotope, Inc. with isotope enrichment of $97 \%$. They were used as delivered. The samples were heated up to $400 \mathrm{~K}$ and the temperatures were controlled using a proportional integral differential (PID) unit. In order to test for any thermal decomposition, mass spectra were recorded at different temperatures. No differences were observed in relative peak intensities as a function of temperature. The extraction region and the TOF system were heated during the measurements in order to prevent any sample condensation and thus charge accumulation on the electrodes.

\section{THEORETICAL METHOD}

The charge transfer in the collision of a neutral potassium atom and a nucleobase is described in the framework of the molecular representation looking at the evolution of the quasi-molecular system formed by the potassium projectile and the biomolecular target along the reaction coordinate. The one-dimension coordinate approximation is applied, as in previous ion/neutral-biomolecule collision systems. ${ }^{29-31}$ The atom-nucleobase collision system is thus treated as a pseudo-diatomic molecule evolving along the coordinate associated with the distance between the impinging atom and the nucleobase. ${ }^{32,33}$ This approach does not consider the internal degrees of freedom of the biomolecule but may be used for very fast collision processes where nuclear vibration and rotation motions are much slower than the collision time and can be frozen during the collision.

The geometry of adenine and 9-mAd has been optimized at the MP2 level of theory from the work of Fuentes-Cabrera et al. ${ }^{34} \mathrm{~A}$ perpendicular approach of the potassium atom pointing at the N9 atom (see Fig. 1) has been considered, as the charge transfer process has clearly been shown to be favoured in this orientation for the case of pyrimidine targets. ${ }^{35,36} \mathrm{Ab} \mathrm{ini-}$ tio molecular calculations have been carried out with the MOLPRO code. ${ }^{37}$ The nucleobase targets are kept frozen in their ground state geometry during the collision process. The
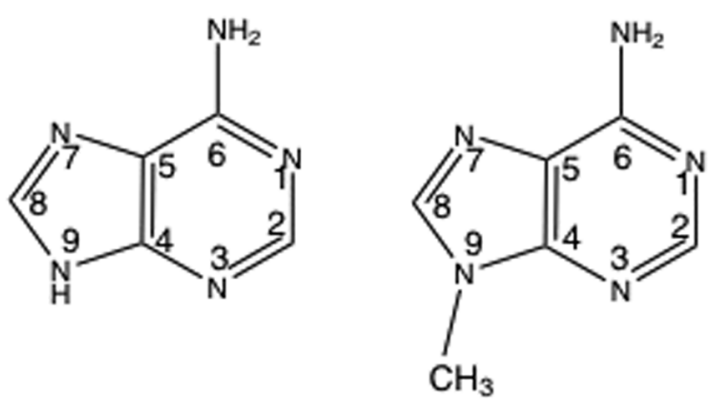

adenine

9-methyl adenine

FIG. 1. Molecular structure of adenine and 9-methyl adenine. 
calculation has been performed in Cartesian coordinates, with no symmetries. All electrons have been considered for $\mathrm{C}, \mathrm{N}$, and $\mathrm{H}$ atoms with the $6-311 \mathrm{G}^{* *}$ basis set although the 18 core electrons of potassium have been treated through the ECP18sdf core-electron pseudopotential, ${ }^{38}$ with the corresponding basis set. The natural molecular orbitals for the K-Ad and K-9-mAd have been determined by state-averaged CASSCF calculations for the reaction coordinate $\mathrm{R}=10 \AA$ corresponding to the asymptotic region. Similar active spaces have been considered for both targets in order to compare each system at the same level of accuracy. The 1s orbitals of carbon, nitrogen, and oxygen are treated as frozen cores. The resultant highest occupied molecular orbitals (HOMOs) and lowest unoccupied molecular orbitals (LUMOs) for adenine and 9-methyl adenine are shown in Fig. 2 together with the corresponding orbitals without the presence of potassium cation. For adenine orbitals,

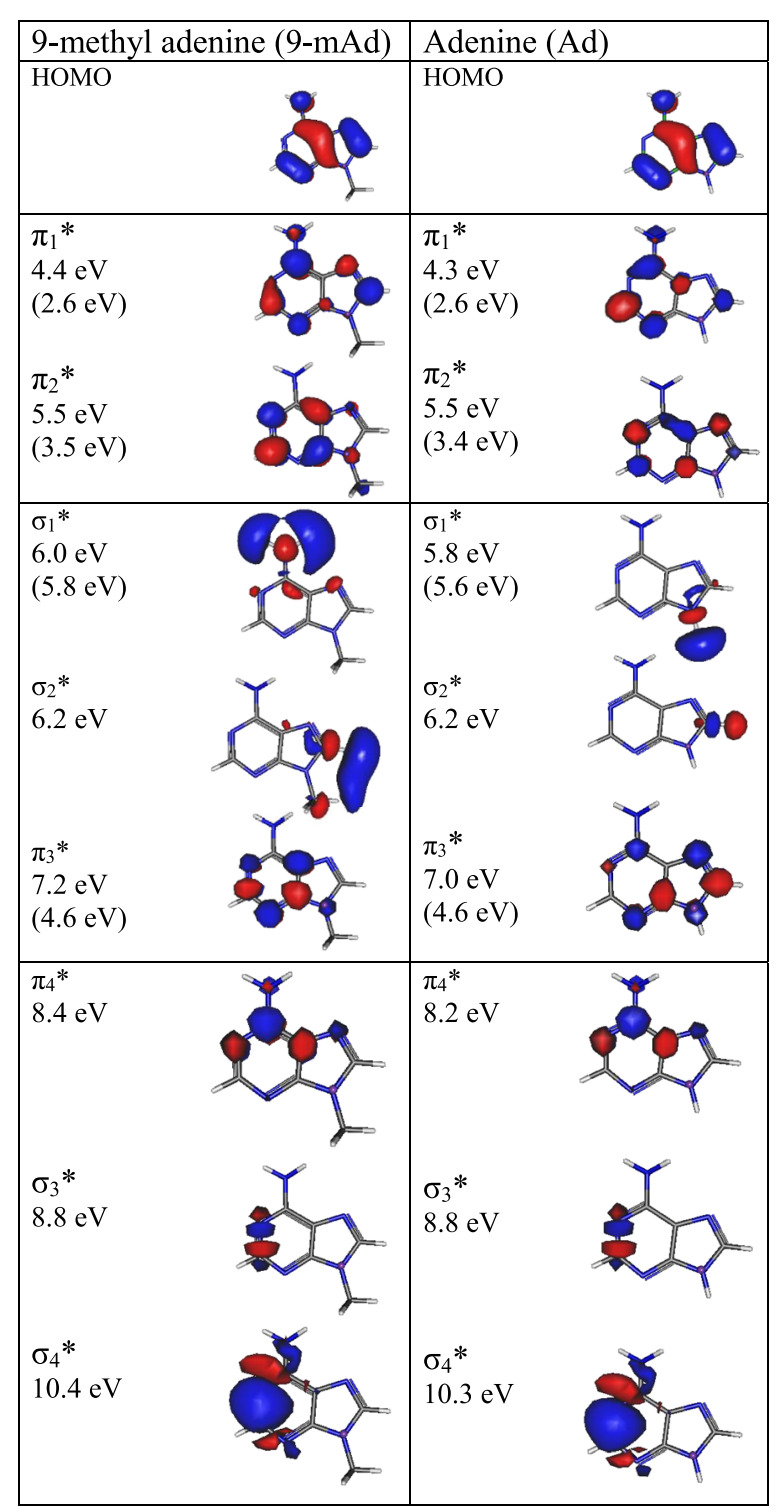

FIG. 2. Calculated highest occupied molecular orbitals (HOMOs) and lowest unoccupied molecular orbitals (LUMOs) for 9-methyl adenine (9-mAd) and adenine (Ad) in the presence of a potassium cation atom in the perpendicular geometry pointing on the N9 atom. In parenthesis values calculated without the presence of potassium. Energies in $\mathrm{eV}$. the present results are in good agreement with a recent study using the Complex Absorbing Potential/Symmetry Adapted Cluster-Configuration Interaction (CAP/SAC-CI) method. ${ }^{39}$ The polarization by the potassium cation induces a global shift in energy of about $2 \mathrm{eV}$ for the $\pi$ orbitals but the effect remains weak on the $\sigma$ orbitals.

\section{RESULTS AND DISCUSSION}

Our recent short communication on electron transfer from neutral potassium atoms to $\mathrm{Pu}, \mathrm{Ad}, 9-\mathrm{mAd}, 6-\operatorname{dimAd}$, and 2-DAd showed that dehydrogenated parent anion formation can be achieved by selective breaking of $\mathrm{C}-\mathrm{H}$ or $\mathrm{N}-\mathrm{H}$ bonds, depending on the collision energy. ${ }^{11}$ Based on the same experiments, the present work extends the analysis to the full fragmentation pattern of the TNIs. The two papers are complementary and the reader is recommended to read both for a full investigation of the collision dynamics. Dissociative electron transfer TOF mass spectra were recorded at lab-frame collision energies of $12-100 \mathrm{eV}(3.8-68.3 \mathrm{eV}$ in the centre-of-mass frame and from now on referred as available energy). Table I is a compilation of all fragment anions detected at 12, 15, 30, 50,70 , and $100 \mathrm{eV}$ lab frame collision energies.

Figure 3 shows the negative ion TOF mass spectra recorded at $30 \mathrm{eV}$ for $\mathrm{Pu}, \mathrm{Ad}$, and 6-dimAd, Fig. 4 for $\mathrm{Ad}$ and $\mathrm{Pu}$ at $70 \mathrm{eV}$, and Fig. 5 for 2-DAd and 9-mAd at $100 \mathrm{eV}$ lab frame collision energies with neutral potassium atoms. Branching ratios (BRs) for the major fragments of $\mathrm{Ad}$ and $\mathrm{Pu}$ as a function of the collision energy are presented in Fig. 6. The TOF mass spectra show no evidence of parent anion formation $\left(\mathrm{M}^{-}\right)$and are, generally speaking, dominated by the cyanide anion $\left(\mathrm{CN}^{-}\right)$. The absence of $\mathrm{M}^{-}$formation is unsurprising since the vertical electron affinity of adenine is $-0.54 \mathrm{eV} .^{9}$ The loss of different HCN units from the dehydrogenated parent anion of $\mathrm{Pu}$ and $\mathrm{Ad},(\mathrm{M}-\mathrm{H})^{-}$, is schematically presented in Table I (see discussion in Sec. IV C). Another interesting aspect to discuss is the role of the potassium cation in the vicinity of the temporary negative ion (TNI) formed upon electron transfer, i.e., $\mathrm{K}+\mathrm{M} \rightarrow\left(\mathrm{K}^{+} \mathrm{M}^{-}\right)$and how the strong Coulomb interaction may affect the decomposition of the TNI. This is comprehensively investigated here and a mechanism is proposed with the help of quantum chemical calculations below. From the calculations, we also note that the lowest-lying $\pi^{*}$ states are considerably shifted to higher energies $(\sim 2 \mathrm{eV})$ in the presence of a potassium cation (some of the calculated MOs without the presence of $\mathrm{K}^{+}$appear in parentheses in Fig. 2).

Finally, accessing a $\pi^{*}$ state does not lead to direct bond breaking unless a repulsive $\sigma^{*}$ state is crossed diabatically. However, the available energy is enough to give access to intramolecular electron transfer $(\pi \rightarrow \sigma)$, which is possible if the nuclear wavepacket survives long enough along the reaction coordinate to allow diabatic coupling between the two states. This is discussed below within the scope of the different $\pi^{*}$ and $\sigma^{*}$ MOs involved in the formation of particular fragment anions.

\section{A. $(\mathrm{M}-\mathrm{H})^{-},(\mathrm{M}-2 \mathrm{H})^{-}$, and $(\mathrm{M}-3 \mathrm{H})^{-}$}

The dehydrogenated closed shell anion $(\mathrm{M}-\mathrm{H})^{-}$is observed for all the molecular targets studied here and is 
TABLE I. Negative ions formed in potassium collisions with purine (Pu), adenine (Ad), 9-methyl adenine (9-mAd), 6-dimethyl adenine (6-dimAd), and adenine-2-d (2-DAd). Arrows indicate loss of HCN.

\begin{tabular}{|c|c|c|c|c|c|}
\hline Mass (u) & $\mathrm{Pu}$ & Ad & 9-mAd & 6-dimAd & 2-DAd \\
\hline 1 & $\mathrm{H}^{-}$ & $\mathrm{H}^{-}$ & $\mathrm{H}^{-}$ & & \\
\hline 15 & $\mathrm{NH}^{-}$ & & & & \\
\hline 16 & $\mathrm{NH}_{2}^{-}$ & $\mathrm{NH}_{2}^{-}$ & $\mathrm{NH}_{2}^{-}$ & & \\
\hline 26 & $\mathrm{CN}^{-}$ & $\mathrm{CN}^{-}$ & $\mathrm{CN}^{-}$ & $\mathrm{CN}^{-}$ & $\mathrm{CN}^{-}$ \\
\hline 38 & & $\mathrm{C}_{2} \mathrm{~N}^{-}$ & $\mathrm{C}_{2} \mathrm{~N}^{-}$ & & \\
\hline 40 & & & $\mathrm{CN}_{2}{ }^{-} / \mathrm{C}_{2} \mathrm{H}_{2} \mathrm{~N}^{-}$ & & \\
\hline 41 & $\mathrm{CHN}_{2}{ }^{-} / \mathrm{C}_{2} \mathrm{H}_{3} \mathrm{~N}^{-}$ & $\mathrm{CHN}_{2}{ }^{-} / \mathrm{C}_{2} \mathrm{H}_{3} \mathrm{~N}^{-}$ & $\mathrm{CHN}_{2}{ }^{-} / \mathrm{C}_{2} \mathrm{H}_{3} \mathrm{~N}^{-}$ & $\mathrm{CHN}_{2}^{-} / \mathrm{C}_{2} \mathrm{H}_{3} \mathrm{~N}^{-}$ & $\mathrm{CHN}_{2}{ }^{-} / \mathrm{C}_{2} \mathrm{H}_{3} \mathrm{~N}^{-}$ \\
\hline 42 & $\mathrm{CH}_{2} \mathrm{~N}_{2}{ }^{-} / \mathrm{C}_{2} \mathrm{H}_{4} \mathrm{~N}^{-}$ & $\mathrm{CH}_{2} \mathrm{~N}_{2}{ }^{-} / \mathrm{C}_{2} \mathrm{H}_{4} \mathrm{~N}^{-}$ & & & \\
\hline 50 & & $\mathrm{C}_{3} \mathrm{~N}^{-}$ & $\mathrm{C}_{3} \mathrm{~N}^{-}$ & & $\mathrm{C}_{3} \mathrm{~N}^{-}$ \\
\hline 55 & & & $\mathrm{C}_{3} \mathrm{H}_{5} \mathrm{~N}^{-}$ & & \\
\hline 64 & $\mathrm{C}_{3} \mathrm{~N}_{2}^{-}$ & $\mathrm{C}_{3} \mathrm{~N}_{2}^{-}$ & $\mathrm{C}_{3} \mathrm{~N}_{2}^{-}$ & & $\mathrm{C}_{3} \mathrm{~N}_{2}^{-}$ \\
\hline 65 & {$\left[(\mathrm{CN})_{2} \mathrm{HC}\right]^{-} \leftarrow$} & {$\left[(\mathrm{CN})_{2} \mathrm{HC}\right]^{-} \leftarrow$} & & {$\left[(\mathrm{CN})_{2} \mathrm{HC}\right]^{-}$} & {$\left[(\mathrm{CN})_{2} \mathrm{HC}\right]^{-}$} \\
\hline 79 & & & $\mathrm{C}_{4} \mathrm{H}_{3} \mathrm{~N}_{2}^{-}$ & & \\
\hline 80 & & & $\mathrm{C}_{4} \mathrm{H}_{3} \mathrm{~N}_{2}^{-} \leftarrow$ & & \\
\hline 92 & $(\mathrm{Pu}-\mathrm{H}-\mathrm{HCN})^{-} \leftarrow$ & $\mathrm{C}_{5} \mathrm{H}_{4} \mathrm{~N}_{2}^{-}$ & & $\mathrm{C}_{5} \mathrm{H}_{4} \mathrm{~N}_{2}^{-}$ & \\
\hline 96 & & $\mathrm{C}_{3} \mathrm{H}_{4} \mathrm{~N}_{4}^{-}$ & & & \\
\hline 107 & & $\mathrm{C}_{4} \mathrm{H}_{3} \mathrm{~N}_{4}^{-}$ & $\mathrm{C}_{4} \mathrm{H}_{3} \mathrm{~N}_{4}{ }^{-} \leftarrow$ & & \\
\hline 108 & & $\mathrm{C}_{4} \mathrm{H}_{4} \mathrm{~N}_{4}^{-}$ & & & \\
\hline 117 & & {$\left[\mathrm{Ad}-\mathrm{H}\left(\mathrm{NH}_{3}\right)\right]^{-}$} & & & \\
\hline 118 & $(\mathrm{Pu}-2 \mathrm{H})^{-}$ & & & & \\
\hline 119 & $(\mathrm{Pu}-\mathrm{H})^{-}$ & $\left(\mathrm{Ad}-\mathrm{NH}_{2}\right)^{-}$ & & & \\
\hline 120 & & & & & $\left(2-\mathrm{DAd}-\mathrm{NH}_{2}\right)^{-}$ \\
\hline 132 & & $(\mathrm{Ad}-3 \mathrm{H})^{-}$ & & & \\
\hline 133 & & $(\mathrm{Ad}-2 \mathrm{H})^{-}$ & $\left(9-\mathrm{mAd}-\mathrm{HCH}_{3}\right)^{-}$ & $\left(6-\operatorname{dim} A d-\left(\mathrm{CH}_{3}\right)_{2}\right)^{-}$ & \\
\hline 134 & & $(\mathrm{Ad}-\mathrm{H})^{-}$ & $\left(9-\mathrm{mAd}^{-\mathrm{CH}_{3}}\right)^{-}$ & & \\
\hline 135 & & & & & $(2-\mathrm{DAd}-\mathrm{H})^{-}$ \\
\hline 146 & & & & $\left(6-\operatorname{dimAd}-\mathrm{NH}_{3}\right)^{-}$ & \\
\hline 147 & & & $(9-\mathrm{mAd}-2 \mathrm{H})^{-}$ & & \\
\hline 148 & & & $(9-\mathrm{mAd}-\mathrm{H})^{-}$ & $\left(6-\operatorname{dimAd}-\mathrm{CH}_{3}\right)^{-}$ & \\
\hline 160 & & & & $(6-\operatorname{dim} \mathrm{Ad}-3 \mathrm{H})^{-}$ & \\
\hline 162 & & & & $(6-\operatorname{dim} A d-H)^{-}$ & \\
\hline
\end{tabular}

formed via the ion-pair reaction

$\mathrm{K}+\mathrm{M} \rightarrow\left(\mathrm{K}^{+} \mathrm{M}^{-}\right) \rightarrow \mathrm{K}^{+}+(\mathrm{M})^{\#-} \rightarrow \mathrm{K}^{+}+(\mathrm{M}-\mathrm{H})^{-}+\mathrm{H}$.

Reaction (1) represents a direct cleavage of the $(\mathrm{C}-\mathrm{H})$ and/or $(\mathrm{N}-\mathrm{H})$ bonds (the specific $\mathrm{H}$ removal can be selected using the collision energy as reported in Ref. 11) and (M) $)^{\#-}$ means a TNI formed with an excess of internal energy. Formation of the parent ion with $\mathrm{H}$ abstraction has been reported in DEA experiments on adenine through vibrational Feshbach resonances ${ }^{14}$ and a weak " $0 \mathrm{eV}$ " contribution, the latter attributed to vibrationally excited molecules. ${ }^{6}$ Adenine BRs as a function of the available energy [Fig. 6(a)], show that $(\mathrm{Ad}-\mathrm{H})^{-}$is the most abundant fragment anion in the low energy collision region and its threshold of formation is below $4.0 \mathrm{eV}$ (12 eV in the lab frame). This is consistent with DEA resonances at 1.07 and $1.4 \mathrm{eV}\left(1.36 \mathrm{eV}^{9}\right)$ attributed to $\mathrm{N} 9-\mathrm{H}$ excision and $2.2 \mathrm{eV}\left(2.17 \mathrm{eV}^{9}\right)$ to $\mathrm{C} 6 \mathrm{~N}-\mathrm{H}$ bond breaking. ${ }^{14}$ Another interesting aspect of the adenine BRs is that the $(\mathrm{Ad}-\mathrm{H})^{-}$yield is generally speaking $\geq 50 \%$ below $16 \mathrm{eV}$ and strongly dominates at $6.1 \mathrm{eV}$. Above this energy, the $(\mathrm{Ad}-\mathrm{H})^{-}$BR decreases while the $(\mathrm{CN})^{-}$BR increases, becoming dominant above $30 \mathrm{eV}$. This indicates that the dehydrogenated parent anion is a precursor in the formation of other fragment anions (except $\mathrm{NH}_{2}{ }^{-}$formation, see the discussion below).

Although $(\mathrm{Pu}-\mathrm{H})^{-}$[Fig. 6(b)] is the dominant fragment anion from purine at $\mathrm{K}$ collision energies below $16 \mathrm{eV}$, it only accounts for $(70 \pm 7) \%$ of the total anion yields at $5.8 \mathrm{eV}$ and falls to just $(35 \pm 7) \%$ at $3.8 \mathrm{eV}$ available energy. At this low collision energy ( $12 \mathrm{eV}$ in the lab frame), $(\mathrm{Pu}-\mathrm{H})^{-}$and $\mathrm{NH}^{-}$ are the prevalent yields, with the latter contributing to $20 \%$ of the fragmentation pattern. By analogy with adenine where the threshold for $\mathrm{H}$ abstraction from $\mathrm{N} 9$ in DEA experiments is $0.94 \mathrm{eV},{ }^{14}$ we expect that any fragment anion has to be formed after $\mathrm{H}$ abstraction from purine TNI. We also observe strong competition with $\mathrm{CN}^{-}$formation which is visible at lab frame collision energies above $30 \mathrm{eV}$ for both adenine and purine.

From Table I, we observe loss of more than one hydrogen atom from $\mathrm{Pu}, \mathrm{Ad}, 9-\mathrm{mAd}$, and 6-dimAd. In the case of 2DAd, we have detected (2-DAd-H) ${ }^{-}$only at $100 \mathrm{eV}$ lab frame collision energy. Huber et al.' ${ }^{6}$ DEA experiments on adenine have reported the loss of two $\mathrm{H}$ atoms through reactions 

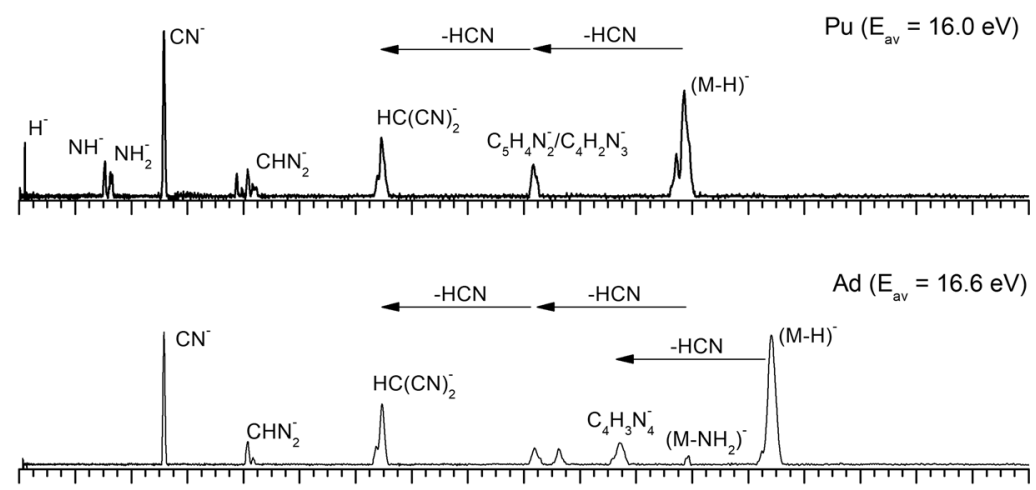

FIG. 3. Time-of-flight negative ion mass spectra in potassium-purine $(\mathrm{Pu})$, -adenine $(\mathrm{Ad})$ and -6-dimethyl adenine (6-dimAd) collisions at $30 \mathrm{eV}$ lab frame energy (16.0, 16.6, and 17.4 eV available energy in the centreof-mass, respectively). See the text for details.

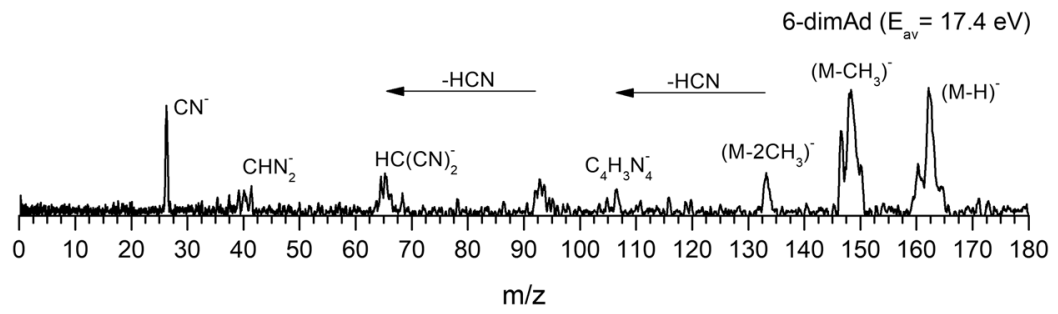

yielding $(\mathrm{M}-2 \mathrm{H})^{-}+\mathrm{H}_{2}$ and/or $(\mathrm{M}-2 \mathrm{H})^{-}+2 \mathrm{H}$ formation. Loss of $\mathrm{H}_{2}$ was attributed to the $0.7 \mathrm{eV}$ resonance whereas $\mathrm{H}+\mathrm{H}$ formation was accessible from the two high energy resonances at 7 and $10.6 \mathrm{eV}$, and loss of an $\mathrm{H}_{2}+\mathrm{H}$ (or three $\mathrm{H}$ atoms) was reported at 6.5 and $10.9 \mathrm{eV}$ resonances. ${ }^{6}$ As these fragment anions are discernible in the present mass spectra above a lab frame collision energy of $30 \mathrm{eV}(16.6 \mathrm{eV}$ available energy), we conclude that these reactions are also accessible in potassiumadenine collisions. The proposed interpretation of the lack of $(\mathrm{M}-\mathrm{D})^{-}$signal from 2-DAd is based on strong autodetachment competing with dissociation as well as to the lack of electron spin density in the $\mathrm{C} 2$ position. For more details, see Ref. 11. Finally, the underlying molecular mechanisms yielding $(\mathrm{M}-2 \mathrm{H})^{-}$and $(\mathrm{M}-3 \mathrm{H})^{-}$formation are still not yet clear although we suggest $\mathrm{H}_{2}$ or $2 \mathrm{H}$ formation for the former (depending on the specific anionic states involved) and the loss of $\mathrm{H}_{2}$ plus an $\mathrm{H}$ radical or $\mathrm{H}+\mathrm{H}+\mathrm{H}$, for the latter, as proposed by Huber and co-workers. ${ }^{6}$ In the case of 2-DAd, however, (M-HD) ${ }^{-}$formation is absent which can be related to the lack of electrostatic potentials around $\mathrm{C} 2$ as well as to enhanced autodetachment due to isotopic labeling. Further investigations are needed to clarify these processes, notably with isotopic labeling in other positions.

\section{B. $\left(\mathrm{M}-\mathrm{CH}_{3}\right)^{-}$and $\left(\mathrm{M}-\mathrm{NH}_{2}\right)^{-}$}

Formation of $\left(\mathrm{M}-\mathrm{CH}_{3}\right)^{-}$and $\left(\mathrm{M}-\mathrm{NH}_{2}\right)^{-}$from potassium collisions with 9-methyl adenine occurs at $67 \mathrm{eV}$ in the centreof-mass frame (see Fig. 5). The electron spin densities in Fig. 2 for 9-methyl adenine suggest that the electron may be initially
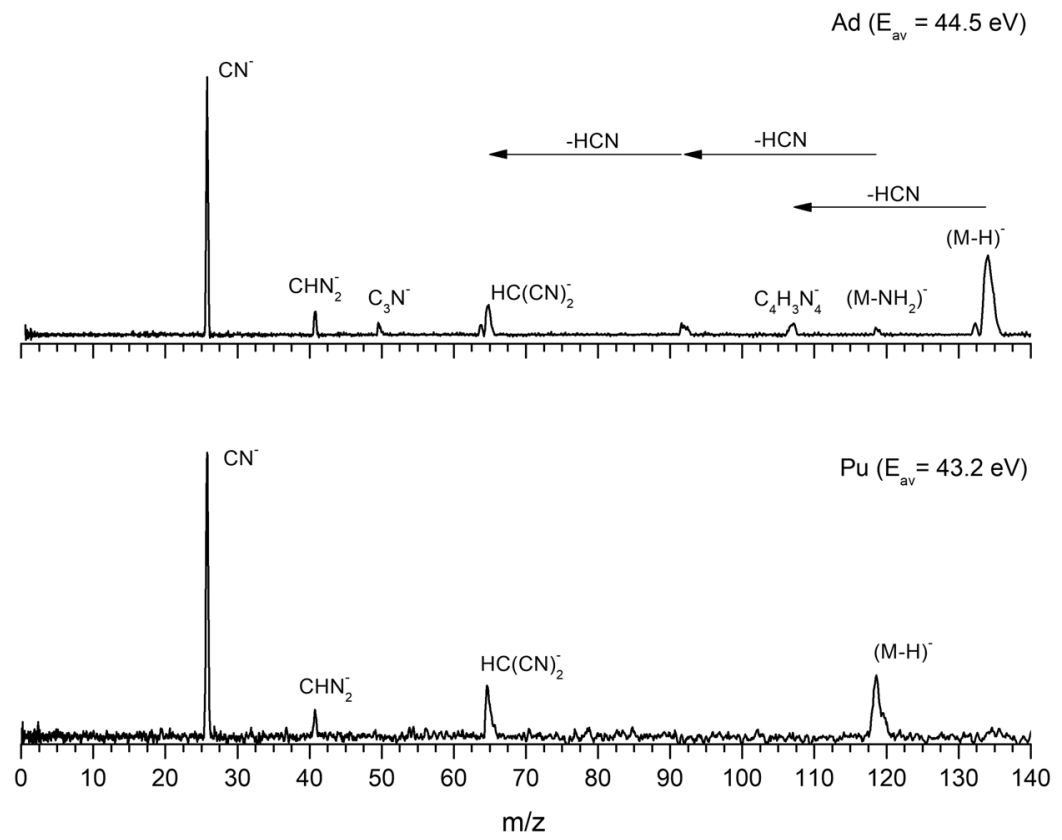

FIG. 4. Time-of-flight negative ion mass spectra in potassium-adenine $(\mathrm{Ad})$ and -purine $(\mathrm{Pu})$ collisions at $70 \mathrm{eV}$ lab frame energy (44.5 and $43.2 \mathrm{eV}$ available energy in the centre-of-mass, respectively). See the text for details and note that an alterative view of these results is presented in our recent communication about formation of dehydrogenated parent anions $\left[(\mathrm{M}-\mathrm{H})^{-}\right]($Ref. 11). 

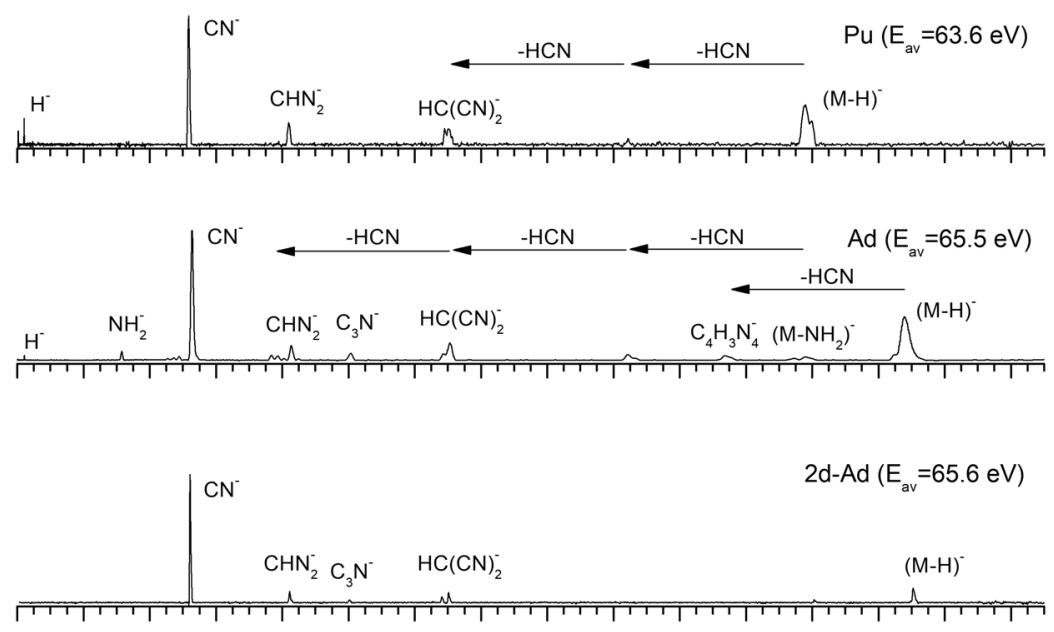

FIG. 5. Time-of-flight negative ion mass spectra in potassium-purine $(\mathrm{Pu})$, -adenine $(\mathrm{Ad})$, -adenine-2-d (2DAd), -9-methyl adenine (9-mAd) and collisions at $100 \mathrm{eV}$ lab frame collision energy $(63.6,65.5,65.6$, and $67.0 \mathrm{eV}$ available energy in the centre-of-mass frame, respectively). See the text for details.

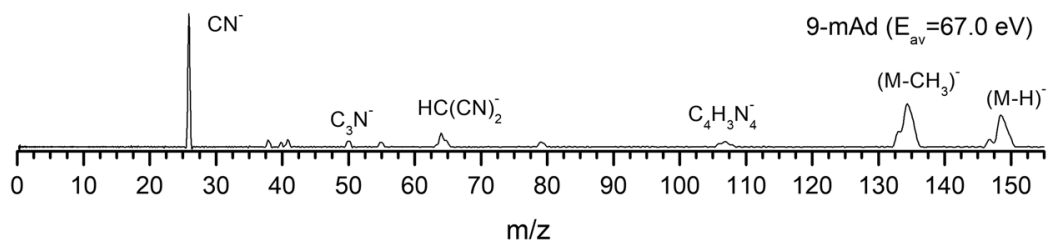

transferred to the $\pi_{2}{ }^{*}$ and $\pi_{3}{ }^{*}$ states and subsequently to the $\sigma_{1}{ }^{*}$ state, resulting in dissociation. Alternatively, a direct initial transfer to the $\sigma_{1}{ }^{*}$ state and subsequent dissociation may occur. The present work does not provide evidence to assess the relative contributions of these two plausible pathways. It is interesting to note that similar dynamics have been discussed by Almeida et al..$^{40}$ in pyrimidine bases. In the case of 3-methyl uracil, the closeness of the vertical transition energies of the $\pi^{*}$ and $\sigma^{*}$ states did not allow us to specify the dominant pathway to dissociation.

The loss of a $\mathrm{CH}_{3}$ group is only visible from 9-mAd and 6-dimAd (respectively, yielding ions with $\mathrm{m} / \mathrm{z} 134$ and 148-see Figs. 3 and 5) but there is no evidence for these channels at $15 \mathrm{eV}$ lab frame. ${ }^{11}$ This suppression can be rationalised in terms of a slow collision process $(\sim 68 \mathrm{fs})$ enhancing Coulomb stabilization of the TNI by the proximate $\mathrm{K}^{+}$ion, increasing the probability of intramolecular electron transfer that may favour dissociation (as is the case for $\mathrm{NH}_{2}{ }^{-}$formation, see Sec. IV F) or may favour autodetachment (suppressing dissociation). As far as authors are aware, no DEA experiments have been produced these fragment anions.

Now we turn to the loss of an $\mathrm{NH}_{2}$ group from adenine (Table I) producing a negative ion with $\mathrm{m} / \mathrm{z} 119$ (see also Fig. 3). The DEA data of Huber et al. ${ }^{6}$ reveal a dissociation channel at low electron energies, with a notably strong resonance feature at $0 \mathrm{eV}$ indicating an exothermal character to the decomposition reaction. The TOF mass spectrum at $12 \mathrm{eV}$ (not shown here) and $15 \mathrm{eV}$ lab frame collision energy ${ }^{11}$ shows no traces of $\left(\mathrm{Ad}-\mathrm{NH}_{2}\right)^{-}$formation. This can be explained under the same rationale of longer transit time of $\mathrm{K}^{+}$near the TNI promoting either autodetachment or an alternative dissociation, which are reasonable arguments given the prominent decrease of the BR for $(\mathrm{Ad}-\mathrm{H})^{-}$formation at these energies as well as increasing production of other fragment anions [see Fig. 6(a)].

\section{Loss of $\mathrm{HCN}$}

Hydrogen cyanide abstraction is more evident in the TOF mass spectra of $\mathrm{Pu}, \mathrm{Ad}$, and 9-mAd (Fig. 5) leading to ring opening, with assignment of the fragment anions indicated in Table I, where arrows indicate the sequential HCN abstractions. The HOMOs of Ad and 9-mAd in Fig. 1 are localized on the rings showing relevant $\pi$ character, while the LUMOs appear with strong $\pi^{*}$ antibonding with nodes along the $\mathrm{C}-\mathrm{N}$ bonds. Such electron spin densities are indicative of favourable bond breaking in particular where curve crossing in the diabatically frame description may be relevant (i.e., $\pi_{4}{ }^{*} / \sigma_{2}{ }^{*}$ ). Though such cleavage, e.g., C2-N1, C4-N3, and C5-N7, C8-N9, may leave the remaining neutral $\mathrm{HCN}$ intact.

Within the collision energy range studied for adenine and its derivatives, i.e., for the available energy $(3.8-68.3 \mathrm{eV})$, such loss of HCN units is operative since the estimated threshold of the decomposition reaction requires $3.89 \mathrm{eV}$ given that $\Delta_{\mathrm{f}} H_{g}{ }^{\circ}$ $\left(\mathrm{C}_{5} \mathrm{H}_{5} \mathrm{~N}_{5}\right)=225.7 \mathrm{~kJ} / \mathrm{mol}(2.34 \mathrm{eV}),{ }^{41} \Delta_{\mathrm{f}} H_{g}{ }^{\circ}\left(\mathrm{C}_{4} \mathrm{H}_{3} \mathrm{~N}_{4}\right)^{-}$ $=248 \mathrm{~kJ} / \mathrm{mol}(2.57 \mathrm{eV}),{ }^{42} \Delta_{\mathrm{f}} H_{g}{ }^{\circ}(\mathrm{HCN})=135.14 \mathrm{~kJ} / \mathrm{mol}$ $(1.4 \mathrm{eV}),{ }^{42}$ and $\Delta_{\mathrm{f}} H_{g}{ }^{\circ}(\mathrm{H})=218 \mathrm{~kJ} / \mathrm{mol}(2.26 \mathrm{eV}) .{ }^{42}$ It is interesting that the loss of $\mathrm{HCN}$ from 9-mAd follows methyl abstraction from the TNI, whereas in Pu and Ad, it takes place after dehydrogenation of the parent anion. In the case of adenine, Huber et al. ${ }^{6}$ reported that fragment anion $107 \mathrm{u}$, $\left(\mathrm{C}_{4} \mathrm{H}_{3} \mathrm{~N}_{4}\right)^{-}$, is formed through loss of HCN from the dehydrogenated parent anion since this reaction is energetically more favourable than the $\mathrm{CN}$ radical and $\mathrm{H}_{2}$ formation.

\section{D. $\mathrm{C}_{3} \mathrm{~N}^{-}$}

The formation of fragment anion with $\mathrm{m} / \mathrm{z} 50$ from Ad, 9-mAd, and 2-DAd (Fig. 5) is just visible at $100 \mathrm{eV}$ lab frame collision energy and totally suppressed at $15 \mathrm{eV} .{ }^{11}$ Harrison and Tennyson ${ }^{43}$ have recently reported that $\mathrm{C}_{3} \mathrm{~N}^{-}$supports a number of low-lying dissociative TNI states. The BR of 


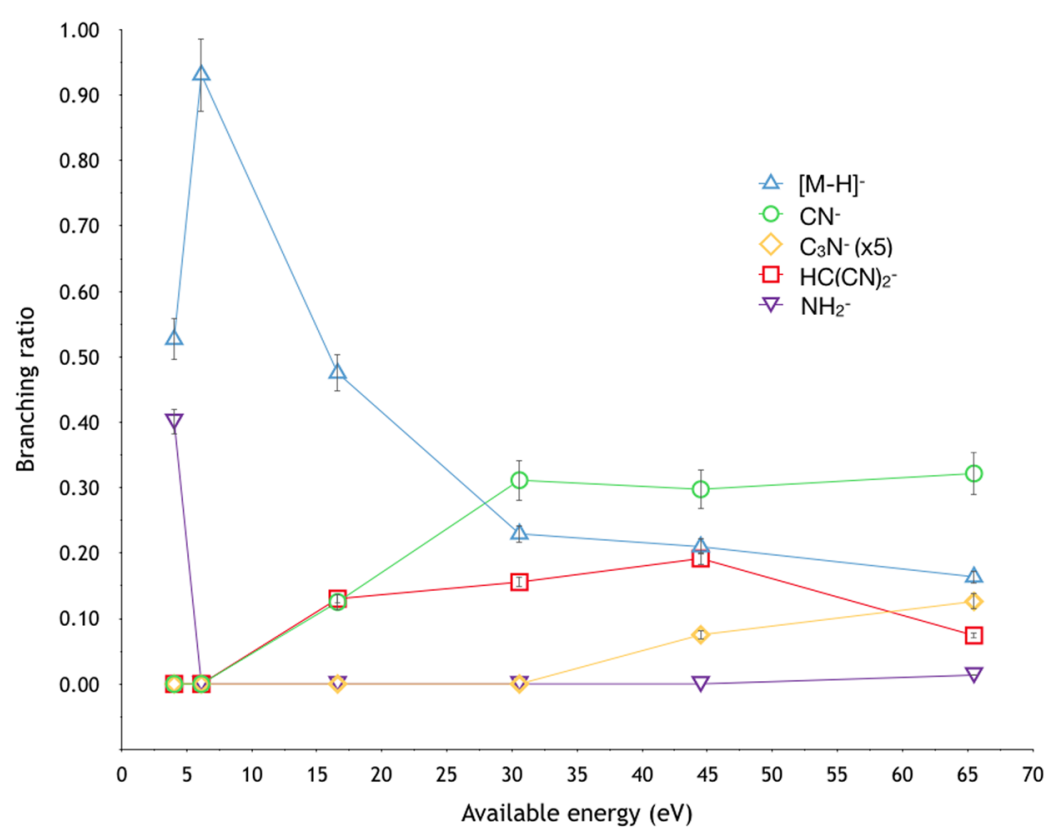

(a)

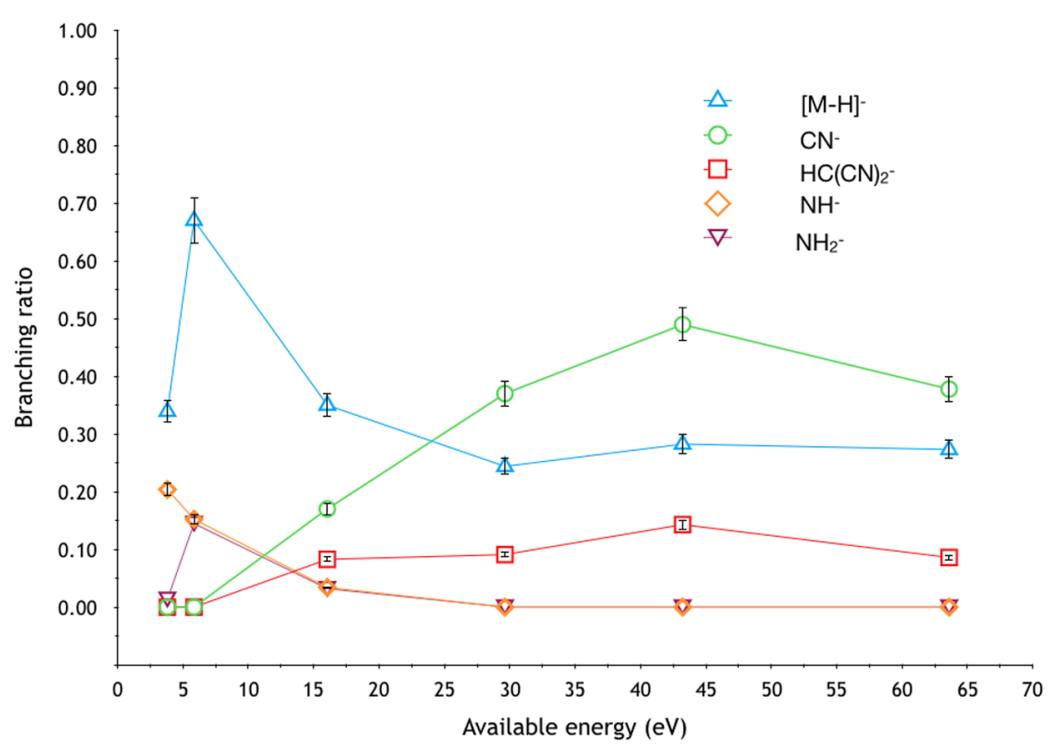

(b)
FIG. 6. Branching ratios (fragment anion yield/total anion yield) as a function of the collision energy in the centre-of-mass frame: (a) adenine (Ad); (b) purine ( $\mathrm{Pu}$ ). See the text for details.
$\mathrm{C}_{3} \mathrm{~N}^{-}$in Fig. 6(a) shows the threshold of formation at $\sim 31 \mathrm{eV}$ available energy and increases as a function of the collision energy. We also observe that above this energy, the cyanide anion is present in the BRs. Although $\mathrm{C}_{3} \mathrm{~N}$ has higher electron affinity $\left(4.54 \mathrm{eV}^{44}\right)$ than $\mathrm{CN}\left(3.862 \mathrm{eV}^{45}\right)$, the former anion results from combined fragmentation of both of rings with a considerable energy requirement. Owing to the molecular structure of $\mathrm{Ad}, \mathrm{C}_{3} \mathrm{~N}^{-}$can only result from the pyrimidinelike structure decomposition whereas $\mathrm{CN}^{-}$formation may proceed from the breaking of the five-membered ring in particular in the lower energy regime (see discussion below). Interesting to note that we have previously observed $\mathrm{C}_{3} \mathrm{~N}^{-}$ fragments from potassium collisions with thymine. ${ }^{46} \mathrm{We}$ suggest that in the case of adenine, this fragment anion may be formed via concerted mechanisms involving the six-membered ring.

\section{E. $\mathrm{CN}^{-}$}

The TOF mass spectra in Fig. 5 at $100 \mathrm{eV}$ lab frame collision energy are dominated by the cyanide anion, whereas at low collision energies, only $(\mathrm{M}-\mathrm{H})^{-}, \mathrm{H}^{-}, \mathrm{NH}^{-}$, and $\mathrm{NH}_{2}{ }^{-}$are discernible. ${ }^{11}$ Hence we can conclude that in the unimolecular decomposition process, the dehydrogenated parent anion is a precursor in the formation of fragments that require bond cleavages in the rings, namely, $\mathrm{CN}^{-}$. Such a decomposition process was previously observed for the pyrimidines investigated in collisional electron transfer experiments. ${ }^{47}$ DEA experiments on adenine show that $\mathrm{CN}^{-}$is the most intense anion at electron energies above $5 \mathrm{eV}$, with resonances at 5.8, 6.7, and $11.5 \mathrm{eV}^{6}$ In order to aid our understanding of the underlying molecular mechanisms and the accessed states that are responsible for $\mathrm{CN}^{-}$formation in adenine-potassium 
collisions, Fig. 2 shows three calculated $\pi^{*}$ orbitals at $4.3 \mathrm{eV}\left(\pi_{1}{ }^{*}\right), 5.5 \mathrm{eV}\left(\pi_{2}{ }^{*}\right)$, and $7.0 \mathrm{eV}\left(\pi_{3}{ }^{*}\right)$. At higher energies, two $\sigma^{*}$ resonances at $8.8\left(\sigma_{3}{ }^{*}\right)$ and $10.3 \mathrm{eV}\left(\sigma_{4}{ }^{*}\right)$ are present, with $\sigma_{3}{ }^{*}$ along the $\mathrm{C} 2-\mathrm{N} 1$ bond. Note that there is no appreciable difference compared with the energies of the 9-mAd LUMOs. Accordingly, the adenine BRs in Fig. 6(a) show that $\mathrm{CN}^{-}$cannot be produced $\leq 6.1 \mathrm{eV}(\leq 15 \mathrm{eV}$ collision energy) which can be related to an electron promotion to the $\pi_{2}{ }^{*} / \pi_{3}{ }^{*}$ orbital. Accessing $\pi_{3}{ }^{*}$ is achieved by increasing the collision energy, and hence the $\mathrm{CN}^{-}$yield, with bond-breaking certainly occurring through access of the $\sigma^{*}$ states. Now, a question that stands to be answered is where does $\mathrm{CN}^{-}$formation proceed from? At threshold, is it initially formed from the fragmentation of the five-membered ring or is it the result of a combined contribution of breaking both rings? A careful inspection of Fig. 5 (100 eV lab-frame collision energy) for Ad and 9-mAd shows a weak fragment anion at $107 \mathrm{u}$ that has been assigned in Table I to $\left(\mathrm{C}_{4} \mathrm{H}_{3} \mathrm{~N}_{4}\right)^{-}$but is totally suppressed at $15 \mathrm{eV}$ lab frame collision energy. ${ }^{11}$ The BRs in Fig. 6 indicate that fragment anions (with the exception of $\mathrm{NH}_{2}{ }^{-}$) result from decomposition of the dehydrogenated parent anion, and this rationale also holds for 9-mAd. By analogy with Denifl et al.' ${ }^{14}$ DEA experiments, this signifies that $\mathrm{H}$ abstraction is already operative at $\sim 1 \mathrm{eV}$. In the case of potassium-adenine collisions, the dehydrogenated parent anion may be formed with an excess of internal energy resulting in fragmentation yielding two complementary channels

$$
\begin{aligned}
& (\mathrm{M}-\mathrm{H})^{\#-} \rightarrow \mathrm{CN}^{-}+\left(\mathrm{C}_{4} \mathrm{H}_{3} \mathrm{~N}_{4}\right)+\mathrm{H} \\
& (\mathrm{M}-\mathrm{H})^{\#-} \rightarrow \mathrm{CN}+\left(\mathrm{C}_{4} \mathrm{H}_{3} \mathrm{~N}_{4}\right)^{-}+\mathrm{H}
\end{aligned}
$$

These fragmentation pathways may proceed through two routes which involve breaking of N1-C6 and C6-C5 bonds (six-membered ring), and N7-C8 and N9-C4 bonds (fivemembered ring). $\left(\mathrm{C}_{4} \mathrm{H}_{3} \mathrm{~N}_{4}\right)^{-}$formation may proceed from both routes at high collision energies, typically $100 \mathrm{eV}$ in the lab frame. Breaking N7-C8 and N9-C4 bonds is the most probable route at low collision energies, corresponding to the calculated $\pi_{2}{ }^{*}$ and $\pi_{3}{ }^{*}$ molecular orbitals, and most likely leading to the formation of $\mathrm{CN}^{-}$in view of its high electron affinity $(3.8620$ $\pm 0.0050 \mathrm{eV}){ }^{42}$

\section{F. $\mathrm{NH}_{2}{ }^{-}$and $\mathrm{NH}^{-}$}

The TOF mass spectrum of $\mathrm{Pu}$ at $15 \mathrm{eV}$ lab frame collision energy ${ }^{11}$ shows a significant contribution of $\mathrm{NH}^{-}$and $\mathrm{NH}_{2}{ }^{-}$ relative to the $(\mathrm{Pu}-\mathrm{H})^{-}$yield. In the case of $\mathrm{Ad}$ at $12 \mathrm{eV}$ [see its BR in Fig. 6(a)], we observe that $\mathrm{NH}_{2}^{-} /(\mathrm{Ad}-\mathrm{H})^{-}$appears at a ratio of $\sim 1: 2$. The $\mathrm{NH}_{2}{ }^{-}$threshold of formation from adenine in DEA was estimated at $\sim 3.1 \mathrm{eV}$ given that $D\left(\mathrm{C}-\mathrm{NH}_{2}\right)$ $=3.9 \mathrm{eV}^{5}$ and $\mathrm{EA}\left(\mathrm{NH}_{2}\right)=(0.771 \pm 0.005) \mathrm{eV}^{48}$ The BRs in Fig. 6 show that $\mathrm{NH}_{2}{ }^{-}$is not formed by dissociation of the dehydrogenated parent anion. At $12 \mathrm{eV}$ lab frame collision energy, the available energy amounts to $4.0 \mathrm{eV}$ which is enough to yield the $\mathrm{NH}_{2}$ anion. At $6.1 \mathrm{eV}$ available energy ( $15 \mathrm{eV}$ in the lab frame), the TNI is formed with an excess of internal energy which can be statistically distributed over the internal degrees of freedom, resulting in $\mathrm{NH}_{2}{ }^{-}$formation even with a modest electron affinity. This assumption seems reasonable since the electrostatic potential maps of Ad show a region of positive electron spin density around the $-\mathrm{NH}_{2}$ group. ${ }^{14}$ However, the high relative intensity of the $\mathrm{NH}_{2}{ }^{-}$signal in the present data at low collision energies can only be attributed to the presence of $\mathrm{K}^{+}$in the vicinity of the TNI allowing intramolecular electron transfer from the ring to $-\mathrm{NH}_{2}$. In the case of $\mathrm{Pu}, \mathrm{NH}^{-}$, and $\mathrm{NH}_{2}{ }^{-}$, the formation mechanism may substantially differ from Ad. The isodensity map of purine in Ref. 14 shows that the region strongly favourable for electron capture is around the N9-H and the neighbouring $\mathrm{C} 8-\mathrm{H}$ sites. As such, $\mathrm{NH}^{-}$formation upon electron transfer to purine may proceed through the breaking of C4-N9 and C8-N9 bonds and electron capture at $\mathrm{NH}$. Taking $D(\mathrm{C}-\mathrm{N})=3.1 \mathrm{eV}$ and $\mathrm{EA}(\mathrm{NH})=(0.370 \pm 0.004)$ $\mathrm{eV},{ }^{42}$ the estimated threshold is $5.83 \mathrm{eV}$. The available energy at a lab-frame collision energy of $15 \mathrm{eV}$ is slightly higher than this value and hence this formation mechanism is plausible in the present experiments. Finally, regarding $\mathrm{NH}_{2}{ }^{-}$formation from purine, we note from Fig. 6(b) that its yield is slightly lower than $\mathrm{NH}^{-}$formation. The $\mathrm{NH}_{2}^{-} / \mathrm{NH}^{-}$ratio remains approximately constant when the collision energy is increased to $30 \mathrm{eV}$ lab frame [16 eV available energy, Fig. 6(b)], indicating that the two fragments derive from a common excited precursor. The mechanism for amino radical anion formation must involve $\mathrm{NH}$ combining with a proton transferred from the $\mathrm{C} 8$ position. Identifying the specific mechanism is beyond the scope of this contribution and quantum chemical calculations would be very helpful clarifying the routes of $\mathrm{NH}_{2}{ }^{-}$ formation.

\section{G. $\mathbf{H}^{-}$}

The formation of $\mathrm{H}^{-}$can be represented by the reaction

$$
\mathrm{K}+\mathrm{M} \rightarrow \mathrm{K}^{+}+(\mathrm{M})^{\#-} \rightarrow \mathrm{K}^{+}+(\mathrm{M}-\mathrm{H})+\mathrm{H}^{-} .
$$

The $\mathrm{H}^{-}$yield is clearly visible in $30 \mathrm{eV}$ lab frame collisions (Fig. 3) from Pu only. We do not have a strong basis to explain the absence (with the present signal/noise ratios) of this anion in the equivalent mass spectra of Ad and 6-dimAd. Huber et $a l .{ }^{6}$ have reported $\mathrm{H}^{-}$formation via two resonances at 6 and $11 \mathrm{eV}$, the former almost three times more intense than the latter. The resonance at $6 \mathrm{eV}$ may be accessed in a potassium collision at $15 \mathrm{eV}$ lab frame ( $\sim 6 \mathrm{eV}$ available energy). We observe $\mathrm{H}^{-}$formation from adenine in $100 \mathrm{eV}$ lab frame collisions (Fig. 5), albeit with a very low yield. This may suggest that its absence in the present measurements at low collision energies is linked to strong competition with other fragment anion channels with energetically similar resonances.

\section{CONCLUSIONS}

The present work provides a comprehensive investigation of the decomposition mechanisms of $\mathrm{Pu}, \mathrm{Ad}, 9-\mathrm{mAd}$, 6-dimAD, and 2-DAd in collisions with potassium atoms. The major fragment anion channels have been investigated as a function of the available energy in the centre-of-mass frame. In the case of adenine, the dehydrogenated parent anion is shown to be a precursor in the formation of the smaller fragment anions, with the exception of $\mathrm{NH}_{2}{ }^{-}$. We report for the first time formation of $\left(\mathrm{M}-\mathrm{CH}_{3}\right)^{-}$from 9-mAd and 6$\operatorname{dim} \mathrm{Ad}$. Additionally, $\mathrm{C}_{3} \mathrm{~N}^{-}$formation is proposed to proceed through decomposition of the six-membered ring structure, 
while the cyanide anion may proceed from the breaking of the five-membered ring particularly in low energy collisions. The theoretical calculations reveal how the electronic structures of Ad and 9-mAd are modified by the presence of the electron donor and hence provide insights into the electronic states that are most likely to participate in the major fragment anion channels. The clear differences in fragment anion production from adenine in the present electron transfer collisions compared with DEA provide further evidence that the specifics of the electron delivery mechanisms need to be properly taken into account in nanoscale models of radiation damage to DNA.

\section{ACKNOWLEDGMENTS}

T.C., M.M., and F.F.d.S. acknowledge the Portuguese National Funding Agency FCT-MCTES through Nos. SFRH/BD/52538/2014, PD/BD/106038/2015, and researcher position IF-FCT IF/00380/2014, respectively, and together with PLV the research Grant No. UID/FIS/00068/2013. This work was also supported by Radiation Biology and Biophysics Doctoral Training Programme (RaBBiT, No. PD/00193/2010); No. UID/Multi/04378/2013 (UCIBIO). G.G. acknowledges partial financial support from the Spanish Ministerio de Economia, Industria y Competitividad (Project No. FIS2016-80440). S.E. acknowledges the support of the British EPSRC through a Career Acceleration Fellowship (No. EP/J002577/1) and a Research Grant (No. EP/L002191/1). M.-C.B.-M. acknowledges support from the computational resources from the CCIN2P3 in Villeurbanne and CCRT/CINES/IDRIS by GENCI (Grand Equipement National de Calcul Intensif) under the Allocation No. x2017087662.

${ }^{1}$ B. Boudaiffa, P. Cloutier, D. Hunting, M. A. Huels, and L. Sanche, Science 287, 1658 (2000).

${ }^{2}$ I. Baccarelli, I. Bald, F. A. Gianturco, E. Illenberger, and J. Kopyra, Phys. Rep. 508, 1 (2011).

${ }^{3}$ L. Sanche, Nature 461, 358 (2009).

${ }^{4}$ C. R. Wang, J. Nguyen, and Q. Bin Lu, J. Am. Chem. Soc. 131, 11320 (2009).

${ }^{5}$ H. Abdoul-Carime, J. Langer, M. A. Huels, and E. Illenberger, Eur. Phys. J. D 35, 399 (2005).

${ }^{6}$ D. Huber, M. Beikircher, S. Denifl, F. Zappa, S. Matejcik, A. Bacher, V. Grill, T. D. Märk, and P. Scheier, J. Chem. Phys. 125, 84304 (2006).

${ }^{7}$ B. F. Minaev, M. I. Shafranyosh, Y. Svida, M. I. Sukhoviya, I. I. Shafranyosh, G. V. Baryshnikov, and V. A. Minaeva, J. Chem. Phys. 140, 175101 (2014).

${ }^{8}$ C. Desfrançois, H. Abdoul-Carime, and J. P. Schermann, J. Chem. Phys. 104, 7792 (1996).

${ }^{9}$ K. Aflatooni, G. A. Gallup, and P. D. Burrow, J. Phys. Chem. A 102, 6205 (1998).

${ }^{10}$ K. Aflatooni, A. M. Scheer, and P. D. Burrow, J. Chem. Phys. 125, 054301 (2006).

${ }^{11}$ T. Cunha, M. Mendes, F. Ferreira da Silva, S. Eden, G. García, and P. Limão-Vieira, J. Chem. Phys. 148, 021101 (2018).

${ }^{12} \mathrm{H}$. Abdoul-Carime, S. Gohlke, and E. Illenberger, Phys. Rev. Lett. 92, 168103 (2004).

${ }^{13}$ S. Gohlke, H. Abdoul-Carime, and E. Illenberger, Chem. Phys. Lett. 380, 595 (2003).

${ }^{14}$ S. Denifl, P. Sulzer, D. Huber, F. Zappa, M. Probst, T. D. Märk, P. Scheier, N. Injan, J. Limtrakul, R. Abouaf, and H. Dunet, Angew. Chem., Int. Ed. 46, 5238 (2007)

${ }^{15}$ S. Tonzani and C. H. Greene, J. Chem. Phys. 124, 54312 (2006).
${ }^{16}$ M. Harańczyk, M. Gutowski, X. Li, and K. H. Bowen, Proc. Natl. Acad. Sci. U. S. A. 104, 4804 (2007).

${ }^{17}$ C. Fonseca Guerra, F. M. Bickelhaupt, S. Sana, and F. Wang, J. Phys. Chem. A 110, 4012 (2006).

${ }^{18}$ L. M. Salter and G. M. Chaban, J. Phys. Chem. A 106, 4251 (2002).

${ }^{19}$ M. P. Fulscher, L. Serrano-Andres, and B. O. Roos, J. Am. Chem. Soc. 119, 6168 (1997)

${ }^{20}$ A. C. Borin, L. Serrano-Andres, M. P. Fulscher, and B. O. Roos, J. Phys. Chem. A 103, 1838 (1999).

${ }^{21}$ S. Pilling, A. F. Lago, L. H. Coutinho, R. B. de Castilho, G. G. B. de Souza, and A. N. de Brito, Rapid Commun. Mass Spectrom. 21, 3646 (2007).

${ }^{22}$ B. Barc, M. Ryszka, J. C. Poully, E. Jabbour Al Maalouf, Z. El Otell, J. Tabet, R. Parajuli, P. J. M. Van Der Burgt, P. Limão-Vieira, P. Cahillane, M. Dampc, N. J. Mason, and S. Eden, Int. J. Mass Spectrom. 365-366, 194 (2014).

${ }^{23}$ S. Chakrabarti and S. K. Chakrabarti, Astron. Astrophys. 354, L6-L8 (2000).

${ }^{24}$ R. Glaser, B. Hodgen, D. Farrelly, and E. McKee, Astrobiology 7, 455 (2007).

${ }^{25}$ V. P. Gupta, P. Tandon, P. Rawat, R. N. Singh, and A. Singh, Astron. Astrophys. 528, A129 (2011).

${ }^{26}$ D. Almeida, F. Ferreira da Silva, G. García, and P. Limão-Vieira, Phys. Rev. Lett. 110, 023201 (2013).

${ }^{27}$ F. Ferreira da Silva, D. Almeida, R. Antunes, G. Martins, Y. Nunes, S. Eden, G. Garcia, and P. Limão-Vieira, Phys. Chem. Chem. Phys. 13, 21621 (2011).

${ }^{28}$ R. Antunes, D. Almeida, G. Martins, N. J. Mason, G. Garcia, M. J. P. Maneira, Y. Nunes, and P. Limão-Vieira, Phys. Chem. Chem. Phys. 12, 12513 (2010).

${ }^{29}$ D. Almeida, M.-C. Bacchus-Montabonel, F. Ferreira da Silva, G. Garcia, and P. Limão-Vieira, J. Phys. Chem. A 118, 6547 (2014).

${ }^{30}$ M. C. Bacchus-Montabonel and Y. S. Tergiman, Comput. Theor. Chem. 990, 177 (2012).

${ }^{31}$ M. C. Bacchus-Montabonel and F. Calvo, Phys. Chem. Chem. Phys. 17, 9629 (2015).

${ }^{32}$ L. Salem, Electrons in Chemical Reactions: First Principles (Wiley Interscience, New York, 1982).

${ }^{33}$ M. C. Bacchus-Montabonel, D. Talbi, and M. Persico, J. Phys. B: At., Mol. Opt. Phys. 33, 955 (2000).

${ }^{34}$ M. Fuentes-Cabrera, B. G. Sumpter, and J. C. Wells, J. Phys. Chem. B 109, 21135 (2005)

${ }^{35}$ M. C. Bacchus-Montabonel and Y. S. Tergiman, Phys. Rev. A 74, 54702 (2006).

${ }^{36}$ M. C. Bacchus-Montabonel and Y. S. Tergiman, Phys. Chem. Chem. Phys. 13, 9761 (2011)

${ }^{37}$ H.-J. Werner, P. J. Knowles, G. Knizia, F. R. Manby, M. Schütz et al., MOLPRO, version 2015.1, a package of ab initio programs, 2015, see http://www.molpro.net.

${ }^{38}$ A. Nicklass, M. Dolg, H. Stoll, and H. Preuss, J. Chem. Phys. 102, 8942 (1995).

${ }^{39}$ Y. Kanazawa, M. Ehara, and T. Sommerfeld, J. Phys. Chem. A 120, 1545 (2016).

${ }^{40}$ D. Almeida, D. Kinzel, F. Ferreira da Silva, B. Puschnigg, D. Gschliesser, P. Scheier, S. Denifl, G. García, L. González, and P. Limão-Vieira, Phys. Chem. Chem. Phys. 15, 11431 (2013).

${ }^{41}$ O. V. Dorofeeva and N. Vogt, J. Chem. Eng. Data 54, 1348 (2009).

${ }^{42}$ See http://webbook.nist.gov/chemistry/ for NIST Chemistry WebBook, 2018.

${ }^{43}$ S. Harrison and J. Tennyson, J. Phys. B: At., Mol. Opt. Phys. 44, 45206 (2011).

${ }^{44}$ K. Graupner, T. L. Merrigan, T. A. Field, T. G. A. Youngs, and P. C. Marr, New J. Phys. 8, 117 (2006).

${ }^{45}$ S. E. Bradforth, E. H. Kim, D. W. Arnold, and D. M. Neumark, J. Chem. Phys. 98, 800 (1993).

${ }^{46}$ D. Almeida, R. Antunes, G. Martins, S. Eden, F. Ferreira da Silva, Y. Nunes, G. Garcia, and P. Limão-Vieira, Phys. Chem. Chem. Phys. 13, 15657 (2011).

${ }^{47}$ F. Ferreira da Silva, C. Matias, D. Almeida, G. García, O. Ingólfsson, H. D. Flosadóttir, B. Ómarsson, S. Ptasinska, B. Puschnigg, P. Scheier, P. Limão-Vieira, and S. Denifl, J. Am. Soc. Mass Spectrom. 24, 1787 (2013).

${ }^{48}$ C. T. Wickham-Jones, K. M. Ervin, G. B. Ellison, and W. C. Lineberger, J. Chem. Phys. 91, 2762 (1989). 